\title{
Transformation of Novel's Genre in Modern Literature
}

\section{Alua Berikbaykyzy Temirbolat}

Raushan Mamievna Abdikulova

\author{
Salima Abdiramanovna Kalkabaeva
}

\section{Aknur Abduzhaparovna Ospanova}

Al-Farabi Kazakh National University, Kazakhstan, 050040, Almaty, Al-Farabi avenue, 71

Aliya Abduzhaparovna Ospanova

Ahmet Yesevi International Kazakh-Turkish University, Kazakhstan, 161200, SKR, Turkestan, B.Sattarkhanov avenue

Doi:10.5901/mjss.2015.v6n4s2p333

\begin{abstract}
Characteristic features of the genre of novel in literature of late XX - turn of XXI century have been analyzed in the article. Contemporary prose development trends have been revealed on the base of generalization of works covering this problem and analysis of a certain writings. Changes of the genre of novel in writers' works have been revealed and factors that affect development of literary process have been defined. Scientific and technical progress impact on writers' world outlook, authors' concept of being and personality, structure and content of today novels have been revealed. Characteristic features of prose written in late XX - turn of XXI century have been defined. Multilayer, multi-genre nature, polyphony and flexibility of novels have been outlined. Analysis of ideas and topics as well as construction of works of contemporary writers has been paid much attention. Principles and methods of picturing life in prose of late XX - turn of XXI century have been defined. Essence of genre and stylistic originality of contemporary writers have been formulated. Specifics of change of the set of patterns in literature of late XX - turn of XXI century have been revealed. Deepening of psychological insight, authors' attempts to broaden the limits of traditional ideas of the world and reveal hidden sides of characters, pictured phenomena and processes have been stressed.
\end{abstract}

Keywords: novel, genre, writer, creative work, literature, century, transformation, trend, content, form.

\section{Introduction}

Literature of late $X X$ - turn of $X X I$ century has been characterized by intensification of the process of genre transformation. It was caused by renewal of ideas and topics of works and writers' will to find new forms to reveal artistic design deeper and fuller and to picture real life with all its multifaceted character. Intensification of genre transformation "is caused by growing of author's "power" over genre, shift of dominance from genre to author in tandem "genre-author". Author's will generate various shifts and changes of established genre models that causes new genre or intragroup formations" (Zvyagina, 2001).

Contemporary culture development trends play important role in changing of formal structure of works, renewal of style and meaning. Contemporary culture is multi-dimensional, contradictory, multi-lingual in its essence. Its impact has caused new genre forms and variations. Deviation from classic traditions is typical for contemporary literature. Widely spread are works that combine elements of different genre forms like essay novel, parable novel, fairy tale novel, etc.

Contemporary prose is characterized by inclusiveness of content, wide-scale epic narration and sophisticated characters. It causes renewal of the genre of novel that was significantly changed in literature of late XX - turn of XXI century. According to some researchers, combination of different forms of composition may be seen now in the structure of this genre (Sharipov, 1984).

Contemporary literature has been undergoing "dramatic transformation of genre way of thinking that was formed by centuries-old tradition. Wide differentiation and at the same time contamination of genre both in the scope of system and inside one separate work may be observed" (Markova, 2012). Experiments with content and forms of novels are typical for writers of late $X X$ - turn of $X X I$ century that explains an interest of researchers to this problem.

The problem of evolution and transformation of literary genre is the topic of works by M.M. Bakhtin (Bakhtin, 2000), 
N.L. Leiderman (Leiderman, 2010), P.C. Stone (Stone, 1998), L. Santini (Santini, 2014), M. Stein (Stein, 2004), D. Chandler (Chandler, 1997), M.P. Abasheva, F.A. Kataev (Abasheva, Kataev, 2013). V.I. Tiupa (Tiupa, 2011) and others. Researchers discover factors that impact development of literature. Specific features of genre evolution in contemporary prose have been revealed in their works. They also pay much attention to the problem of interaction of literature and culture.

Pressing character of this research is caused by the necessity of deep analysis of the process of novel's genre transformation in contemporary prose, understanding directions of its development and changes of its content and form.

\section{Methods}

Historical and functional, comparative and typological methods, complex, system, hermeneutical approaches were used in this research. They allow at first carrying out integral and all-dimensional analysis of works of authors of late XX - turn of XXI century, and secondly revealing patterns and trends of contemporary prose development. Application of these methods allowed significantly widening horizons of understanding of artistic world of novels.

Complex method aimed on understanding of all levels of poetic manner of prose works helped revealing specific features of the system of aesthetic principles of writers that had an impact of originating and development of the genre of novel in late XX - turn of XXI century. Applying it we have defined methods of realization of authors' ides and understood principles of contemporary prose construction.

System approach that requires viewing objects of research in their unity and interrelationship allowed tracking succession of literary traditions and innovation of writers and study the nature of artistic experiments.

Historical and functional method helped to understand the role and importance of works in today society. Application of this method allowed revealing the reasons of transformation of genre of novel in late XX - turn of XXI century and trace connection of literature and historical development of the mankind.

Comparative and typological method that presupposes generalization, analysis and comparison of writers' works allowed revealing typical patterns of these writers. Trends of development of the genre of novel in contemporary literature were defined using his method.

Hermeneutic approach allowed understanding deep essence of processes, phenomena, images, pictured in works of writers by interpreting their semantics, analysis in context of author's concept and historical and cultural process.

\section{Results}

\subsection{Genre and stylistic individuality of contemporary novel}

Research allowed us to reveal that the work of numerous contemporary writers is characterized by intensification of experiments with genre and style. Trilogy of A. Zhaksylykov «Dreams of cursed» may be an example of this trend. Psychological drama is combined with social and philosophic and intellectual novel. As a result of this combination the plot is not linear. Things are moving in different dimensions and cover memoirs, dreams, imagination of characters. Sensual world is interlaced with rational and irrational ones. Realms of everyday life are being widened to deep philosophical generalizations (Zhaksylykov, 2005).

The novel "The name of the rose" (II nome della Rosa) written by U. Eco is characterized by combination of detective, historical, intellectual novel. Basing on things of distant past the other construct the plot as an investigation of crime committed in Abbey. But the real aim of the search of the novel's protagonist is truth, knowledge and spiritual experience.

The base of novels by $\mathrm{H}$. Murakami is combination of deep psychological insight, philosophical generalizations, memoirs. Elements of fiction, detective, mystery, thriller and anti-utopia are joined in his works. Thinking over the problems of today life author uses them in the canvas of the most unbelievable events in the lives of his characters.

The prose of late XX - turn of XXI century has multi-style nature. Artistic descriptions are often combined with scientific information about a certain events, publicism with spoken word. For example, in the novel «Dead wonder in sands» written by R. Seisenbaev description of events are accompanied by citations from newspapers. The writer uses publicism in his novel to outline the importance of problems he analyzes in the novel and to strengthen the effect on reader. Scientific, artistic and spoken styles are combined in trilogy by A. Zhaksylykov "Dreams of cursed". Characters are citing the works of scientists and spoke about the problems of everyday life. Their remarks contain citations of artistic works. 


\subsection{Ideas and topics of novel of late XX - turn of XXI century}

Multilayer nature is typical for novels of late XX - turn of XXI century. Such levels as historical, philosophical, psychological, the layer of plot and composition may be defined in words of contemporary writers. These layers are tightly interrelated and form a single whole. This may be easily seen in novels by R. Seisenbaev "Dead wonder in sands", A. Nurpeisov's "Last honour", U. Eco's "The name of the rose", Murakami's The Wind-Up Bird's Chronicle, O. Pamuk's "Dzhevded-bei and sons", Ch. Aitmatov's "When the mountains fall (or Eternal bride)". Analysis of inner life of characters, their emotions, feelings, concerns, contradictions and motivations are interlaced with appeal to the history of people, thoughts about eternal ideas of happiness, good, truth, justice.

Modernization of the genre of novel manifests itself on the level of conflict. It has more complicated and contradictory and sometimes insoluble character. This approach allows opening the new facets in characters of novels, making reader think about the problems of contemporaneity (for example, like novels by A. Nurpeisov "Last honour", A. Zhaksylykov's "Dreams of cursed", D. Nakipov's "The ring of ash", U. Eco's "The name of the rose", H. Murakami's The Wind-Up Bird Chronicle, Ch. Aitmatov "When the mountains fall (or Eternal bride)").

Solving conflict in works of today's writers "tends to open the layer of superpersonal, general". In-depth content of things of life is comprehended via the destinies of characters, from position of artistic world as «the second reality». The conflict defines «the scale of correlation of a person and time in novel» because the reality «grows through the conflict» (Alibaev, 1996). Issues risen by authors are concentrated around one central question that arises contradictions and became the cause of people's opposition. For example, Eco's novel contains the conflict between true and false, «secular and spiritual power», the poverty of Christ and richness; erotic and mystic love (Lem, 2007). In trilogy by A. Zhaksylykov "Dreams of cursed" the opposition lies between eternal and temporal, material and spiritual.

\subsection{Principles and approaches of picturing reality}

Contemporary novel is characterized by flexibility (Bakhtin, 2000). It combines variability and traditional character. This feature of novel manifests itself in its capability to transfer the logic of historical changes undergoing in society, in intensification of figurative word, value of metaphoric exposition that is so typical for contemporary writers.

Conditional forms of figurativity that serve as «purposeful, aesthetically valuable method of deformation of reality» and being the cause of tools of style used in literature is widely used in prose of late XX - turn of XXI century (Sheyanova, 2013).

Including of symbolic images and extensive metaphors is characteristic feature of contemporary novels. They enrich the content and give a special expressiveness to arisen issues.

Writers often use the method of exaggeration in description of things that allows picturing a certain thing more deep and in scale (for example, novels by A. Nurpeisov "Last honour", A. Zhaksylykov's "Dreams of cursed").

Dreams have a special place in prose of late XX - turn of XXI century. Including dreams in novel allows author firstly to widen boundaries of space-time continuum, secondly, to think over phenomena of reality, thirdly to explain in details inner life of characters and show dynamics of their feelings and emotions (for example, novels by A. Nurpeisov "Last honour", A. Zhaksylykov's "Dreams of cursed", U. Eco's "The name of the rose", Ch. Aitmatov's "Stormy stop").

Synthesis of real and conditional forms allows writers to «develop colorful multilayer content. Social and everyday realities in addition to traditional meanings get additional philosophical semantics due to artistic means of creation of conditionality» (Sheyanova, 2013) and thus help to reveal ideas and topics of works, author's concept of being and personality.

Such method as mythology is widely used by contemporary authors. Approaching individual problem of a certain individual person writers often widen it to universal, general humanistic scale (for example, novels by A. Nurpeisov "Last honour", R. Seisenbaev's "Dead wonder in sands", A. Zhaksylykov's "Dreams of cursed", D. Nakipov's "The ring of ash", D. Amantai's "Flowers and books", O. Pamuk's "Dzhevded-bei and sons", Ch. Aitmatov's "When the mountains fall (or Eternal bride)").

Things of today reality are often rethought in works of writers of late XX - turn of XXI century via folklore images and motives. Writers include proverbs, sayings, myths, legends, fairy tales in their novels (for example, novels by A. Kekilbaev "The end of legend", D. Amantai's "Flowers and books", Ch. Aitmatov's "When the mountains fall (or Eternal bride)", M. Park's "Angels' landing place", G. Belger's "The house of wanderer"). According to researchers they "make artistic structure of works more complicated, forms multi-dimensional nature of meanings, outline forms of circumlocution, make active signs and symbols, saturate novel with associations and reminiscences" (Zhaksylykov, 1999).

The works of folklore enrich the content of genre of novel. Applying for images and plots of ancient legends, myths, 
fairy tales writers comprehend moral and aesthetic ideals of contemporaneity. Folklore works give novels special colour, individuality and support deeper analysis of risen issues.

Authors of contemporary novels sometimes apply to religion. In narrations about the ways of their characters and reasoning about the things of reality they use such sources as Bible, Koran and Buddhist sources. Authors want to reflect processes that go on in today world in all their multidimensional nature, understand the reasons of conflicts and contradictions, specifics of human consciousness that is why they include religious images and motives in structure and content of novels (for example, A. Zhaksylykov's "Dreams of cursed", U. Eco's "The name of the rose", Ch. Aitmatov's "Execution block").

\subsection{Polyphony of contemporary novel}

Prose of late XX - turn of XXI century is characterized also by polyphony. It may be seen in several levels of novels. First of all polyphony characterizes narration in works of contemporary writers. A. Zhaksylykov's "Signing stones" may serve as an example. Writer joins remarks of several characters in one paragraph without indication who is speaking.

Polyphony is also specific feature of composition, time-space continuum of novels. It manifests itself in joining events completely different in place and period in one paragraph or sentence (for example, novels by A. Zhaksylykov "Signing stones", A. Kim "Father forest") (Temirbolat, 2007).

Social and cultural reality of life of characters which the main action of a work goes in plays the most important role in contemporary novels. Writers often analyze the mind of people who are representatives of traditional world outlook. Writers trace the process of spiritual growth of a man by placing characters in the system of reality of today life. Characters "experience existential state of time that moves facing them with centuries-old problems. The present as endless repetition of sensations of the past, as experiencing moral obligations to the memory of predecessors" (Ismailova, 2007). Examples, novels by A. Nurpeisov "Last honour", R. Seisenbaev's "Dead wonder in sands", A. Zhaksylykov's "Dreams of cursed", A. Kim's "Father forest", Ch. Aitmatov's "Stormy stop".

Novels of contemporary writers are characterized by subject multi-facetedness. It is represented mainly in differentiation of characters' speech and author's word. Dominating points of view of participants of events is constantly changing by the way of narration. Events are described and characterized via perception of author, narrator, characters. Subject multi-facetedness is most vividly seen in A. Zhaksylykov's "Dreams of cursed", D. Nakipov's "The ring of ash", D. Amantai's "Flowers and books", A. Kim's "The island of Jonah", Ch. Aitmatov's "When the mountains fall (or Eternal bride)".

The polyphony of genre is typical for novels late XX - turn of XXI century. It has "collage" nature and is represented in "combination of various, sometimes contrast things and at the same time is oriented on mechanical transformation of these contradicting forms making them integral work" (Pesterev, 2001).

Multi-genre nature enriches the structure and content of prose works. It is the source of individuality of artistic world of writers, it deepens conflict, adds dynamics to plotlines.

Genre polyphony is defined by specifics of a novel itself that becomes the form that is characterized by free development and "does not know any law except narration" (Ropars-Wuellennier, 1997).

Different types of narration, genre variations are natively combined in works of contemporary writers. They make integral whole, a single genre due to the presence of "stable semantic core", that is formed due to "aggregate of dominating artistic methods that override all the other methods used to create the single whole" (Sharifova, 2012). At the same time they preserve individual characteristics that are being reflected in all the levels of poetics and content of a novel that in turn provide for communicativeness and syncretism of prose of late XX - turn of XXI century.

\subsection{Composition of novel of late XX - turn of XXI century}

Genre mixture causes addition of new elements and methods that are realized at the level of narration. Main reasons of this phenomenon are firstly trends of historical and cultural development of today society that cause the necessity of search for new artistic forms, secondly means of communication that have significantly broaden possibilities and horizon of writers, thirdly demand for changes in plot organization, strengthening of intrigue, deepening of life situations and collisions.

Collapsing of social time and space is typical for novels of contemporary writers. As a result their works tend to "move from linear time to cycle time, or to "freezing" of time, to increase of interpenetration of real and surreal" (Sharifova, 2012).

Trend to de-realization of events of works may be seen in novels of late XX - turn of XXI century. It causes 
transformation of story and plot. "Genre memory volume increases due to strengthening of above-generic forms, trends to extra-genre types, including meta-prose, hypertexts" (Sharifova, 2012). This trend is represented in A. Zhaksylykov's "Dreams of cursed", D. Nakipov's "The ring of ash", D. Amantai's «Flowers and books», A. Kim's "The island of Jonah".

Game techniques are often used in structure of works of contemporary writers as a "special sort of anti-mimetic strategy that binds author, text and reader" and that is "aimed on overcoming the power that is realized in mechanisms of language". A game "gives full and deepest freedom placing real heteronymia of things in the heart of servile language" (Lipovetski, 1997). Examples of these trends are D. Amantai's «Flowers and books», D. Nakipov's «The ring of ash», U. Eco's "The name of the rose".

\section{Discussion}

Historical, social and philosophical layers are key semantic levels of novels of late XX - turn of XXI century. Specifics of development of today society, historical and personal destinies of people, moral and ethical categories, universal and eternal problems of being are comprehended in works of writers.

U. Eco, O. Pamuk, H. Murakami, A. Nurpeisov, A. Kim, J. Fowles, R. Seisenbaev, M. Park, G. Belger, D. Nakipov, D. Amantai see reality via the prism of the past. They stress philosophical comprehension of problems of today life. Authors rethink the reasons of contradictions in society. Authors try to reveal the essence of such categories as good and evil, happiness, truth and lie, justice.

Viewing private life in the unity with historical destiny of people, in the context of social reformations is typical for novels of late XX - turn of XXI century. This move in writers' work causes complication of time-space organization of their works. Events described in their works go on in the interface of past, present and future. Personal destiny is being interlaced with universal destiny. The history became integral part of personal life. Examples are R. Seisenbaev's «Dead wonder in sands", A. Nurpeisov "Last honour", O. Pamuk "Dzhevded-bei and sons", O. Elubaev "Lone jurt", Ch. Aitmatov's "When the mountains fall (or Eternal bride)", Murakami's "The Wind-Up Bird's Chronicle". Events of these novels happened in a certain historical period and the life of characters goes on this background. Destiny of characters is inseparably tied with twists and turns of things in today society. Characters think over universal and eternal problems of being.

Contemporary novel is characterized by deepening of psychological insight. Authors pay much attention to understanding of inner life of personality, spiritual and moral evolution of a person. Authors try to understand deep motivations of people's behaviourm reasons of their contradictions and concerns.

Psychological insight defines specific of construction of works because it serves as "active plot-defining and structure-defining factor" (Leites, 1993). In penetrate the reality described by authors, causes the way of things, behaviour and actions of characters. The role of monologue, dialog, lyrical digressions and reasoning in works grows respectfully. Authors pay much attention to details that reveal new facets of characters' nature.

Principle of naturalness and method of "weirding" is widely used in novels of late XX - turn of XXI century. To reveal different features of their characters writers place them in situation of choice. They have to make decisions revealing their moral and ethical characteristics and their spiritual potential.

Method of "weirding" is inseparably connected with communicative function of the genre that causes specifics of its development. Novel is a sort of a sign of matured literary tradition that influences the way reader perceive the work (Chernets, 1982).

Contemporary prose undergoes significant transformations under the influence of communicative situation. The genre of novel is being renewed. Elements of fairy tale, parable, fantasy, essay, stream of consciousness are being included in it. Mixture of elements of different genres of literature and types may be seen in novel of late XX - turn of XXI century. Tragedy, drama, satire are interlaced in structure and content of works of contemporary writers. It causes origination of such genres as novel-essay, novel-drama, novel-fairy tale, novel-parable, etc.

Renewal of genre composition of prose of late XX - turn of XXI century is caused by writers' application to spoken word, to myths. They use folklore plot, images and thus widen the boundaries of artistic world. Content and form of novels are also being enriched. Archetype and intertexts becomes important component of works. Novel receives such features as mythologism, folklorism (for example, A. Kim's "Squirrel", Ch. Aitmatov's "Stormy stop", M. Park's "Angels' landing place").

Prose of late $X X$ - turn of $X X I$ century is being influenced by science. Its progress has an influence on writers' minds, their world outlook, attitude. Scientific discoveries allow viewing the world from completely new points of view. It leads to enriching the content of novels.

Language, image system of artistic works is also changing. Writers use terms and concepts in their works. New 
images typical mostly for scientific literature are being used in novels. Writers access and analyze philosophical concepts and theories, principles of quantum physics, psychology (for example, novels by A. Zhaksylykov "Singing stones", Ch. Aitmatov's "The stamp of Cassandra", A. Kim's "Father forest").

Influence of science causes spreading of such genre as pedagogical novel. Plot of such novels is based in the problem of transformation of personality. This genre has been formed as a result of writers' application to pedagogics and psychology. Using achievements of these sciences writers analyze the models of behaviour, specific features of consciousness of a person.

Contemporary prose is characterized by tension, dramatic character of narration. Reality pictured in novels is contradictory, sometimes cruel and indifferent to a person. The problem of alienation plays the special role in novels of late XX - turn of XXI century. It is the central problem of work of R. Seisenbaev, D. Nurpeisov, D. Amantai, A. Zhaksylykov, H. Murakami, O. Pamuk.

Dramatic character of novels of contemporary writers is realized on the level of psychological state of characters. Reasoning about the things of the reality they sometimes contradict with themselves, with habital foundations and values. Former stereotypes are either being crashed with working out new value scale or result in conflict of personality (for example, novels by R. Seisenbaev "The throne of Satan", D. Amantai's "Flowers and books", O. Pamuk's "Snow", H. Murakami's "The Wind-Up Bird's Chronicle").

Dramatic character is being revealed in the level of author's perception of events of novel, assessment of life collisions, social phenomena. Reasoning about the realities of today being author gives his own opinion that reflects his attitude to problem.

Development of genre of novel in contemporary literature goes in several directions caused by specifics of its content and structure. Firstly, time-space organization of works becomes more complicated. Linear character of chronotop is lost. Time-space characteristics are becoming more fragmented. Secondly, gradual decanonization of the genre of novel goes on the manifests itself in "destruction of traditional value centers, amorphism of genre system of novels, active use of absurd methods by authors" (Sharifova, 2011). Thirdly, structural organization of novels becomes more complicated. Novels of contemporary authors are characterized by mom-linearity of plot. Inserts like stories, episodes, hypertexts, meta-prose are widely used in the structure of novels.

System of images is also changes in contemporary novels. Characters of novels of late XX - turn of XXI century combine elements of epic poetics and poetics of a novel. Writers show protagonist in complicated and controversal relations with outer world - nature, society. Imaged of novels are characterized by indeterminacy, multi-facetedness. Sometimes they carry deep symbolic meaning.

Contemporary writers often go beyond the limits of traditional three- or four-dimensional world. Events sometimes go on in two-dimensional time-space system, in unreal world (for example, novels by A. Kim "Squirrel", "The island of Jonah"). Much attention is paid to subconsciousness of characters. Writers research the world beyond the limit of traditional perception. Universe in its numerous realizations is an object of their comprehension and picturing. Events of novels often go in meta-world (for example, in novels by A. Kim "The island of Jonah", Ch. Aitmatov's "The stamp of Cassandra", trilogy of A. Zhaksylykov "Dreams of cursed").

Prose of late XX - turn of XXI century is characterized by usage of different types of writing, including words and expressions of different national languages and languages of spiritual culture that is caused by processes of globalization and integration that go on in today society.

\section{Conclusion}

Genre of novel in late XX - turn of XXI century has been undergoing significant changes caused by a number of factors, among which there are historical and cultural development of society, scientific and technical progress, will of authors to cover the world in all its multi-facetedness, complicated and controversal character and their interest to deep specific features of character and psychology of a personality.

Words of writers are characterized by growing complexity of time-space organization. Plot loses linearity. Polyphony of time and space becomes specific feature of works.

Literature of late $\mathrm{XX}$ - turn of XXI century is characterized by mixture of styles and genres, that causes origination of new form such as detective novel, social and philosophical novel, historical and philosophical novel, fairy tale novel, parable novel, essay novel, etc.

Scientific and technical progress has great impact on literature and on artistic process. That causes continuous transformation of genre. New forms and variations of literary works originate. In recent years such new genres became popular as movie novel, audio-novel, blog novel, comment-novel that requires special research. Technique of narration is 
being renewed, together with methods of comprehension of reality and revealing character, methods of realization of authors' design.

\section{References}

Abasheva, M.P. \& F.A. Kataev, (2013). Russian prose in internet era: transformation in poetics and author's identity. (Monography). Perm:State Humanitarian Pedaggic University.

Alibaev, Z.A. (1996). Nature of conflict in today Bashkir novels. (Candidate dissertation). Ufa. Retrieved 20.03 .2014 from http://cheloveknauka.com/priroda-konflikta-v-sovremennyh-bashkirskih-romanah

Bakhtin, M. (2000). Epos and novel. St.-Petersburg: Azbuka.

Chandler, D. (1997). An Introduction to Genre Theory. Retrieved 02.03.2014 from http://www.aber.ac.uk/media/Documents/intgenre/ intgenre1.html

Zvyagina, M. Yu. (2009). Phenomenon of author's genre definition in Russian prose of second half of XX - turn of XXI century. Dergachev readings-2008 (p. 109-114). Ekaterinburg.

Ismailova, M. V. (2007). Problems of traditions and genre variability in Chechen novel of 80-90s of XX century. Grozniy. Retrieved 02.03.2014 from http://www.dissercat.com/content/problemy-traditsii-i-zhanrovye-raznovidnosti-v-chechenskom-romane-80-90kh-gg-xx-veka

Leiderman, N. L. (2010). Theory of genre. Ekaterinburg, Ural Department of Russian Academy of Education State Pedagogical University.

Leites, N. S. (1993). Finite and infinite. Thoughts about literature in XX century: viewing the world and poetics. Perm: Perm State University.

Lem, S. (2007). Philosophy of occasion. (Monography). Moscow, AST. Retrieved 02.04.2014 from http://www.e-reading.link/book.php? book $=104140$

Lipovetski, M. (1997). Russian post-modernism: essays about historical poetics. Ekaterinburg: Ural State Pedagogical University.

Markova, T. N. (2012). Russian prose of the turn of XXI century: transformations of forms and constructions. Palmarium academic publishing.

Pesterev, V. A. (2001). Post-modernism and poetics of novel. Historical and literary and theoretical dimensions. Volgograd: Volga State University.

Ropars-Wuellennier, M.C. (1997). Forme et Roman. Literature, 108, 77. Retrieved 02.03.2014 from http://www.magazine-litteraire.com/

Santini, L. E-pistolary novels in the XXIst century we-culture: re-shaping a genre (the transformation of a single expressive form triggered by technological development) Retrieved 02.03.2014 from http://www.academia.edu/3551863/E-pistolary_novels_in_the_ 21st_century_we-culture_re-shaping_a_genre_the_transformation_of_a_single_expressive_form_triggered_by_ technological_ development

Stein, M. (2004) Black British Literature: novels of transformation. Ohio State University.

Stone, R. S. (1998). Picaresque Continuities: Transformations of Genre from the Golden Age to the Goethezeit. New Orleans: University Press of the South, ISBN: 1-889431-40-0.

Temirbolat, A.B. Development trends of contemporary novel of Kazakhstan. (2007). Al-Farabi KazNU Bulletin. Philology series.4 (103) (8-12), 9.

Tiupa, V. I. (2011). Narative strategy of novel. New philological gerald.18 (8-24).

Chernes, L. V. (1982). Genres of literature (problems of typology and poetics).Moscow: MSU.

Sharipov, A. (1984) Tradition and novice in Kazakh literature. Alma-Ata: Mektep.

Sharifova, S. Sh. (2011). Modern trends of development of novel and impact on genre mixture. Proceedings of Samara scientific center of Russian academy of science. 2(5),1236).

Sharifova, S. Sh. (2012). Theoretical aspects of genre diversity of Azerbaijan novel. PhD theses, pp. 5, 21, 20. Moscow, IMLI RAS.

Sheyanova, S. V. (2013). Conditionality as style specifics of contemporary Mordovian novel. Finno-Ugric world, 3(23-27), 24, 27. 